\title{
Advanced approach for degradation of recalcitrant by nanophotocatalysis using nanocomposites and their future perspectives
}

\author{
V. C. Padmanaban ${ }^{2}$ M. S. Giri Nandagopal ${ }^{1}$ - G. Madhangi Priyadharshini ${ }^{2}$. \\ N. Maheswari ${ }^{2} \cdot$ G. Janani Sree ${ }^{2} \cdot$ N. Selvaraju ${ }^{1}$
}

Received: 24 November 2015/Revised: 4 April 2016/Accepted: 12 April 2016/Published online: 25 April 2016

(C) Islamic Azad University (IAU) 2016

\begin{abstract}
Industrial effluents containing persistent pollutants play a significant role in environmental pollution. Classical techniques such as chlorination, coagulation, ion flotation, membrane process and sedimentation that have been used to decontaminate polluted water are incapable of efficient degradation due to the generation of secondary pollutants. Photocatalysis, an advanced oxidation process in which the photoreaction is accelerated by the irradiation of catalyst, has shown efficient degradation of recalcitrant in water system. Usage of nanoparticles as homogenous photocatalyst has become prevalent due to their improved properties such as large surface-to-volume ratio, controlled uniform particle size and its composition which enhances the degradation rate. The recombination of holes and electron pair which is considered to be the limitation in homogenous system can be overcome by nanocomposites or heterogeneous photocatalysts. This system decreases the rate of recombination, leading to effective degradation of individual pollutants because of their enhanced physicochemical and structural properties. In recent years, heterogeneous nanophotocatalytic processes employing titanium dioxide $\left(\mathrm{TiO}_{2}\right)$ and zinc oxide $(\mathrm{ZnO})$ composites have gained immense research interest as an effective wastewater treatment method because of its efficacy in decomposing and mineralizing the hazardous organic and inorganic pollutants utilizing the UV and visible photons.
\end{abstract}

N. Selvaraju

selvaraju@nitc.ac.in

1 Department of Chemical Engineering, National Institute of Technology Calicut, Kozhikode, Kerala 673601, India

2 Center for Research, Department of Biotechnology, Kamaraj College of Engineering and Technology, Virudhunagar, Tamil Nadu 626001, India
This paper reviews about the process, synthesis and parameters influencing photocatalytic reaction and their kinetics with much emphasize on types of nanoparticles and nanocomposites and its application in wastewater treatment.

Keywords Degradation - Nanocomposites · Photocatalysis - Titanium dioxide $\left(\mathrm{TiO}_{2}\right) \cdot \mathrm{Zinc}$ oxide $(\mathrm{ZnO})$

\section{Introduction}

Environmental pollution is one of the serious problems faced by the living system due to the increase in population, industrialization and urbanization. Numerous methods, such as Fenton's method, activated carbon, hydrogen peroxide $\left(\mathrm{H}_{2} \mathrm{O}_{2}\right)$ and sodium hypochlorite $(\mathrm{NaClO})$, have been used to degrade the industrial pollutants, but most of these physical and chemical methods are not much efficient as they lead to secondary pollution. In recent years, advanced oxidation processes (AOP) have been widely employed for treatment of recalcitrant pollutants to more biodegradable molecules by generation of reactive species like hydroxyl radicals. These free radicals can attack most of the organic molecules and degrade them through oxidation process. Photolysis, photofenton process and photocatalysis are some advanced oxidation processes that use light as a driving catalyst to generate hydroxyl radicals which are utilized in the oxidation of pollutants present in water. Among these, one of the most important processes is photocatalysis. Photocatalysis has an extensive application in wastewater treatment and has proved to be a promising technique for the degradation of many organic and inorganic pollutants such as oil spills, organic dyes, persistent 
organic pollutants and pesticides which are resistant to all natural forms of degradation (Wang et al. 2008a). The usage of nanomaterials in degradation of pollutants is employed due to their high catalytic activity and high sorption capacity. Nanoparticles can also be anchored to solid matrices for enhanced activity. Nanophotocatalysis (nanoparticles activated by photons) is an advanced oxidation process, widely used for the removal of trace pollutants present in water streams and air. Nanophotocatalysis is more effective than conventional methods as they have a large surface area-to-volume ratio (Martínez et al. 2011) and possess uniform and controlled particle size, composition and structure (Pant et al. 2012). The oxides of titanium, zinc and iron, sulfides of zinc and nitrides of carbon have been attempted for the photocatalytic degradation of a wide variety of environmental contaminants. $\mathrm{TiO}_{2}$ is stable in UV light and water. It is considered very close to an ideal semiconductor for photocatalysis because of its strong oxidizing power, nontoxicity and long-term photostability. These characteristics make $\mathrm{TiO}_{2}$ as a preferable catalyst (Kwon et al. 2008). $\mathrm{ZnO}$ nanoparticles have been extensively used in water treatment (Eskizeybek et al. 2012) due to their high photocatalytic efficiency, low cost and environmental friendliness (Fig. 1).

Free nanoparticles of titanium dioxide $\left(\mathrm{TiO}_{2}\right)$ (anatase, rutile and $\mathrm{P} 25)$ and zinc oxide ( $\mathrm{ZnO})$ and composites of $\mathrm{TiO}_{2}$ and $\mathrm{ZnO}$ have been widely used in the degradation of contaminants in industrial effluents. Natural radiations emitted by the sun in the visible range $(400-700 \mathrm{~nm})$, and UV range (200-400 nm) can be used for the irradiation of semiconducting nanomaterials. In the UV range, shorter wavelength (UV-B: $290-320 \mathrm{~nm}$ ) and longer wavelength (UV-A: $320-400 \mathrm{~nm}$ ) can be exploited through natural radiation. The UV light of much shorter wavelength (vacuum UV: 100-200 nm) gains much interest in developing advanced oxidation process like nanophotocatalysis. But the efficiency of nanophotocatalytic degradation is reduced by the recombination of electrons and holes generated by the action of photons on the catalytic surface. To prevent the recombination of electron-hole pairs, composites of semiconducting nanoparticles have been employed as photocatalysts due to their improved optoelectronic properties (Pant et al. 2012). They exhibit high and stable photocatalytic activity due to the strong redox ability of photogenerated electron-hole pairs (Eskizeybek et al. 2012). They also aid in the removal of nanoparticles from the system after degradation of pollutants making them stable and reusable (Gad-Allah et al. 2008).

Figure 2 represents the publications on degradation of water pollutants, employing the technique of nanophotocatalysis. The research on degradation of water pollutants using free and nanocomposites started after 1995. The effectiveness shown by nanoparticles in effluent degradation gained interest among the researchers. Thus, by the beginning of twenty-first century the research publication on this area increased. After 2005, the nanoparticles were tested out for treating various categories of effluents by several research groups across the globe. The publications on the area almost tripled from that of the previous 5-year span. After 2010 till 2015, the degradation of wastewater using free nanoparticles and composite nanoparticles were explored in multidimensional perspectives. Various novel nanoparticles have been synthesized, and they were studied for their efficacy in degrading various classes of dyes, pesticides and metals. By summarizing the total publications on degradation of water pollutants using free and composite nanoparticles, it is observed that $1.2 \%$ were published during the time period 1995-2000. It then gradually rose to $5.5 \%$ during $2000-2005$ and to $24.7 \%$ in $2005-2010 ; 68.6 \%$ of the publications were during 2010-2015. There were $1.04 \%$ of publications on replacing free nanoparticles with composites to overcome the constrains in the conventional method during 1995-2000, which then gradually rose to $4.75 \%$ during 2000-2005 and to $18.88 \%$ in $2005-2010$. This technique has gained much attention in recent years (2010-2015) as a potential solution in degrading water pollutants which is shown by the rapid increase in number of publication $(75.14 \%)$ on nanocomposites.

\section{Hazardous effects of pollutants}

Wastewaters released from various industries cause serious problem to the health and general well-being of a man. The presence of recalcitrant in effluents such as dyes, heavy metals, pesticides and other pollutants are toxic to human, aquatic life and microorganisms. Release of untreated effluents into the environment is a source of non-esthetic pollution and eutrophication. Water contaminated with non-biodegradable heavy metals and pesticides is highly toxic as it leads to bioaccumulation and biomagnification. Such deleterious effect of recalcitrant on the environment is a cause for serious concern which attracts many researchers to develop zero discharge technology for the treatment of industrial pollutants.

\section{Process of nanophotocatalytic reactions}

Nanophotocatalysis is a category of redox reactions utilizing light of suitable wavelength to irradiate the semiconducting nanomaterials. Since nanoparticles have good adsorbing property, prior to irradiation with a light source, photocatalyst is mixed with water containing pollutants and 


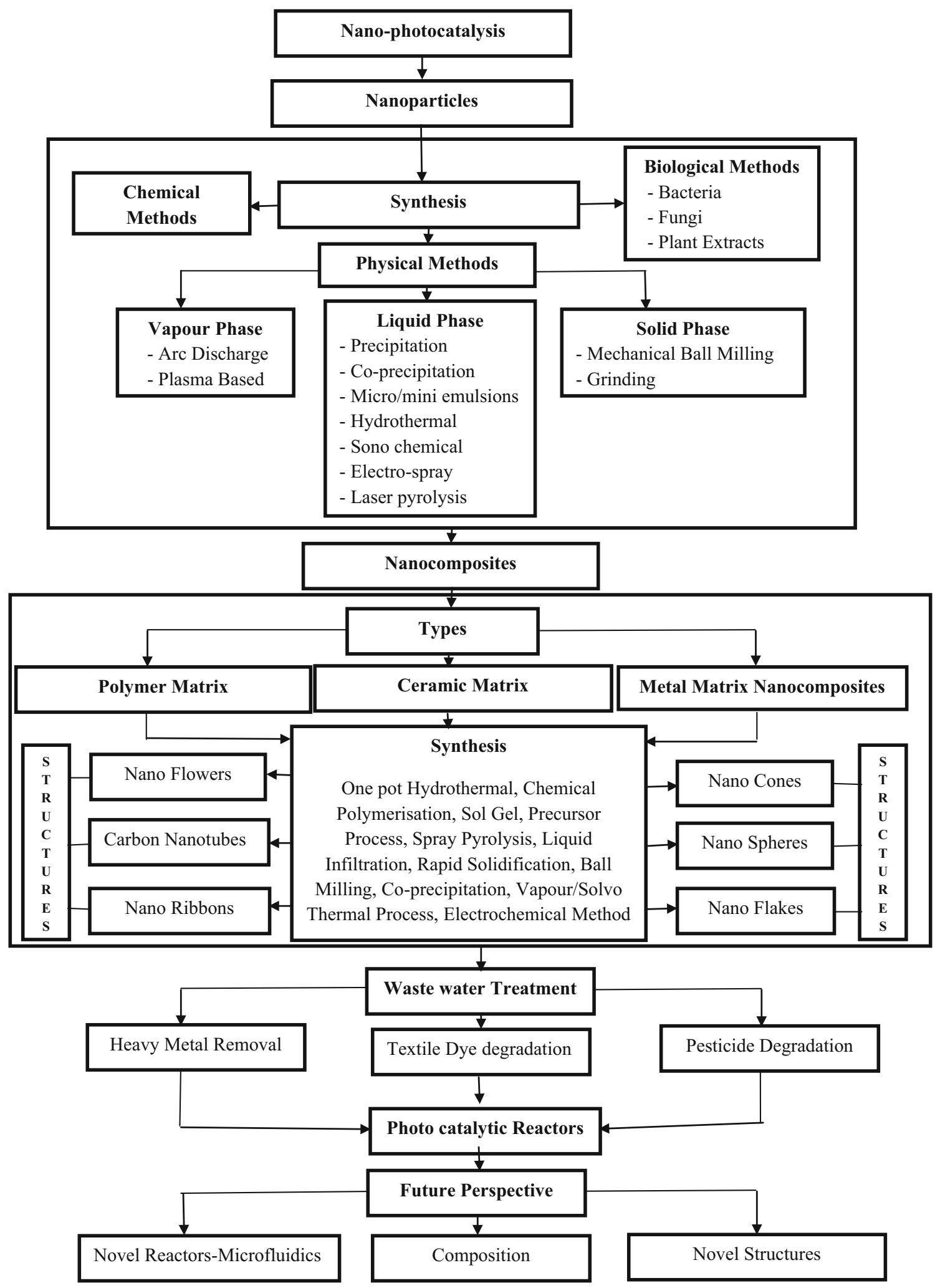

Fig. 1 Outline of nanoparticles and nanocomposites in effluent treatment by nanophotocatalysis and their future perspectives

the suspension is magnetically stirred in dark to reach a complete adsorption-desorption equilibrium of pollutants on the catalyst surface. The suspensions are then illuminated using a suitable light source. On irradiation of semiconductor with a light source, the electrons from the valence band move into the conduction band. As a result, 


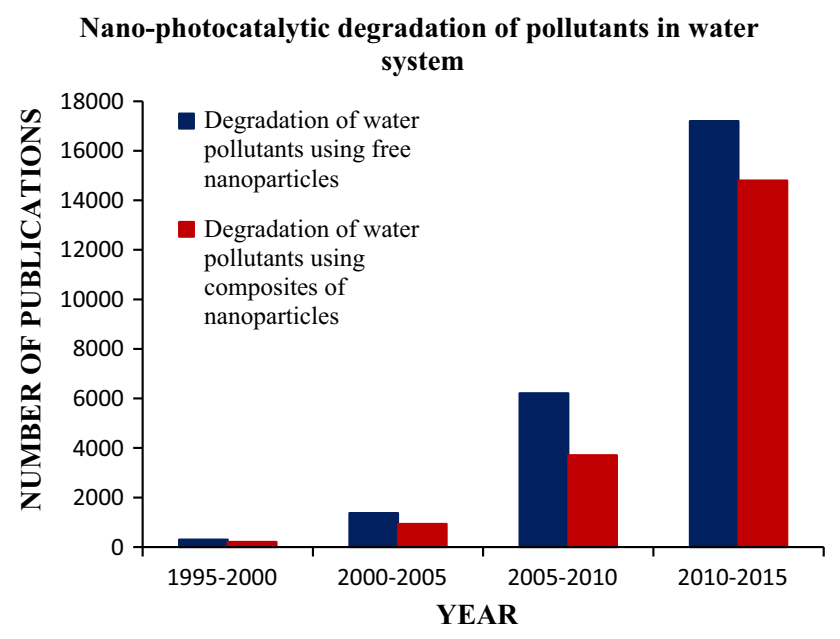

Fig. 2 Number of publications on degradation of water pollutants by free nanoparticles and nanocomposites over past two decades (1995-2015)

same number of holes are generated in valence band. The photogenerated electrons and holes have been found to degrade almost all types of organic, inorganic and microbial contaminants (Martínez et al. 2011), owing to their high redox potentials. They migrate to the surface and react with adsorbed electron donors and electron acceptors to form superoxide radical anions, hydrogen peroxides and hydroxyl radicals (Gad-Allah et al. 2008). The generated hydroxyl radicals can oxidize the organic compounds in aqueous solution, generating non-toxic compounds. Under appropriate reaction conditions, the organic contaminants are completely oxidized to $\mathrm{CO}_{2}$, water and halide ions with minimal generation of undesired by-products.

$\mathrm{NP} / \mathrm{NC}+\mathrm{h} \gamma \rightarrow \mathrm{e}^{-}+\mathrm{h}^{+}$

$\mathrm{h}^{+}+\mathrm{R} \rightarrow \mathrm{R}^{+} \stackrel{\text { Mineralization }}{\longrightarrow} \mathrm{CO}_{2}$

$\mathrm{h}^{+}+\mathrm{H}_{2} \mathrm{O} \rightarrow \mathrm{H}^{+}+\mathrm{OH}$

$\mathrm{OH}+\mathrm{R} \rightarrow$ Oxidation products

$\mathrm{e}^{-}+\mathrm{M}^{n+} \rightarrow \mathrm{M}^{(n-1)+}$

$\mathrm{e}^{-}+\mathrm{h}^{+} \rightarrow$ heat

$\mathrm{e}^{-}+\mathrm{O}_{2} \rightarrow \mathrm{O}_{2}^{-}$

Equation (a) represents generation of photoinduced electrons and holes from nanoparticles (NP). Equation (b) represents the mineralization of recalcitrant pollutants (R) by the holes generated in the system. These holes are also involved in the generation of hydroxyl radicals from water which is represented in Eqs. (c) and (d) which represents the oxidation recalcitrant pollutants by hydroxyl radicals. Equation (e) represents the reduction in heavy metals $\left(\mathrm{M}^{n+}\right)$ by the photoinduced electrons present in the system (Fig. 3).
However, in this process a large proportion of photogenerated electron-hole pairs recombine before the photocatalysis takes place, dissipating the input solar energy and lowering down the photocatalytic efficiency. Equation (f) represents the recombination of the generated electrons and the holes generating heat, an unfavorable reaction which can be prevented by the usage of composites of photocatalytic nanoparticles accounting to their enhanced optoelectronic properties (Gad-Allah et al. 2008; Wang et al. 2011). Equation (g) represents the reaction between oxygen (electronegative atom) and photoinduced electrons resulting in the generation of superoxides $\left(\mathrm{O}_{2}^{-}\right)$, a powerful oxidizing agent. This reaction also prevents the recombination of electrons and holes in the system.

\section{Process parameters}

$\mathrm{pH}$ plays an important role in controlling the efficiency of nanophotocatalysis. Optimal condition is the $\mathrm{pH}$ at which the positively charged nanoparticles and negatively charged pollutant molecules readily attract each other. In this situation, both combine together by hydrogen bonding easily and thus elevate the amount of adsorption and enhance the decomposition rate (Martínez et al. 2011; Xue et al. 2015). Hence, it is essential to determine the point of zero charge of the nanoparticle. Increase in the catalyst dosage increases the total active surface area. Thus, more active sites will be available on the catalyst surface for adsorption and photocatalytic reaction. If the photocatalytic dosage is too high, turbidity will affect the adsorption efficiency. Hence, the photocatalytic dosage must be in optimum quantity (Akpan and Hameed 2009). The photocatalytic degradation rate varies with molar concentration and thus increases with increase in the concentration of

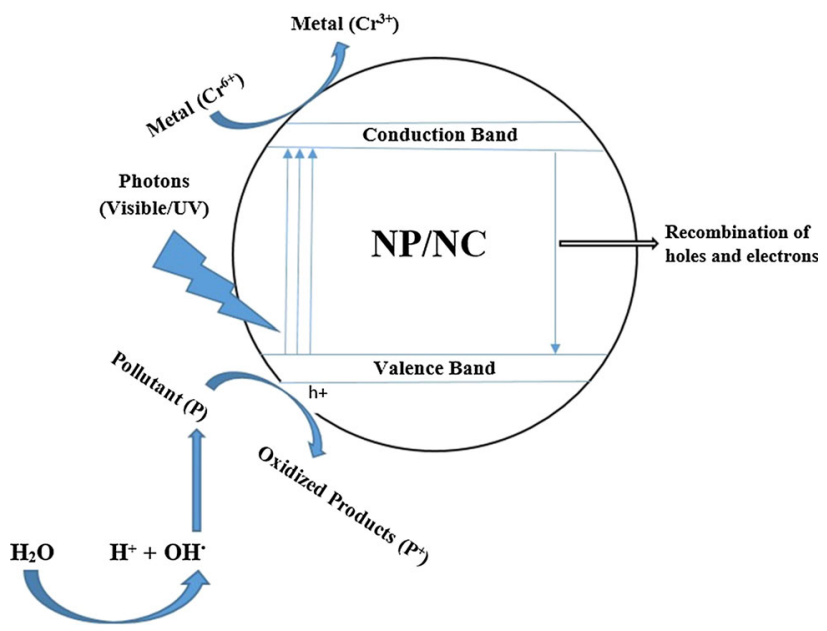

Fig. 3 Schematic representation of nanophotocatalytic degradation 
pollutant by which recombination of holes can be reduced. Increase in pollutant concentration causes increase in the number of excited pollutant molecules. These molecules in their triplet excited state degrade on reacting with photogenerated $\mathrm{OH}$ radicals. But on increasing the pollutant concentration beyond the optimum level, the rate of degradation decreases due to the fact that increase in pollutant concentration decreases the intensity of incident light reaching the surface of the photocatalyst (Mondal and Sharma 2014). From the extensive literature, the key parameters such as $\mathrm{pH}$, concentration of pollutant and concentration of nanophotocatalyst influence the efficiency of the process to greater extent.

\section{Synthesis of nanoparticles}

Nanoparticles play a significant role in accelerating the photocatalytic reactions due to their unique physical, chemical and optical properties. Nanomaterials can be synthesized based on two approaches: "bottom-up" and "top-down." The methodology for developing nanomaterials of desired properties from basic building blocks represents the bottom-up approach. The top-down approach involves resizing macroscale materials into materials of nanosize, and the bottom-up approaches are well suited to synthesize particles of desired and uniform size, shape and structure. The methodologies of preparation of nanoparticles can be categorized into physical, chemical and biological methods. The physical methods employed in the synthesis are on the basis of the phase of nanoparticles such as vapor (arc discharge, plasma, electro spray and laser pyrolysis), liquid (precipitation using surfactants and in micro-/miniemulsion, hydrothermal, sol-gel, sonochemical) and solid (mechanical ball milling). The nanomaterials prepared by physical methods are of wide size ranges whereas by chemical methods are of narrow size range (Liz-Marzán and Kamat 2003; Tavakoli et al. 2007). The chemical methods work on basis of reduction in materials to atoms followed by aggregation of atoms. The usage of reducing agents such as hydrogen, alcohol, $\mathrm{NaBH}_{4}$ and citrate are used in synthesizing narrow range of nanosized particles. The biological molecules produced from bacteria and fungi, and plant extracts are highly efficient in reducing the particles to nanosize.

In the past two decades, novel methods of nanoparticle synthesis for controlled and uniform size have been developed based on the outcomes of numerous research observations. Initially in the mid of twentieth century, the solid-phase synthesis methods by using grinding or milling (top-down approach) are employed in the synthesis of metallic and ceramic nanoparticles. The major disadvantages of these methods such as high energy consumption, high production cost, broad spectrum size distribution, formation of alloys, generation of amorphous particles and impurities are overcome by the next-generation synthesis methods in liquid-phase and gas-phase processes. In liquidphase synthesis methods, the nanoparticles are produced through homogenous or heterogeneous nucleation in supersaturated solutions. Most of the metallic (by the addition of reducing agents to the acidic solution), metal oxides and non-oxidic (appropriate reagents as $\mathrm{H}_{2} \mathrm{~S}$ added for metal sulfides) nanoparticles are synthesized through precipitation and co-precipitation. The morphology and particle reacting properties are controlled by the reaction kinetics. The formation of agglomerates during this process could be avoided by creating a microemulsions (by the addition of biosurfactants which do not require high shear conditions) (Voigt and Sundmacher 2007) where nucleation and particle growth will occur. The development in the precipitation method is the usage of miniemulsions (Landfester 2001). The miniemulsions are produced by introducing shearing into the mixture of two immiscible liquids: a surfactant and an osmotic pressure agent. Stable droplets of sizes between 50 and $500 \mathrm{~nm}$ are produced by suppressing the coalescence and ripening by the surfactants and osmotic pressure agent. In the early twentyfirst century, the next-generation research works focused on the vapor-phase reactions, where the properties of the desired nanoparticles are achieved in the early phases of the reaction by the fluid and particle dynamic interactions (Heidenreich et al. 2003). The smaller particles are formed by achieving supersaturation through higher cooling rate of hot reaction gases used in the synthesis. Hot wall reactor is used for the synthesis of $\mathrm{TiO}_{2}$ and coated nanoparticles from premixed dopant $\left(\mathrm{TiCl}_{4}\right.$ and $\left.\mathrm{AlCl}_{4}\right)$ because of its well-defined flow and temperature regimes and controlled product properties which helps in scaling up the synthesis methods. Non-oxidic materials, materials with high melting points, could be produced in nanoscale by plasma (Kong and Pfender 1997). The energy of plasma generated by ionizing a gas and stripping electrons away from atoms is used for synthesizing nanoparticles. The higher cooling rates in the plasma reactor play a significant role in the formation of metastable and nanoscaled particles at high concentration. Through electrospray pyrolysis, ultrafine droplets are generated by applying high voltage to the liquid surface (Terada et al. 2012). Electrospray coupled with thermal treatment has been used for the synthesis of ceramic particles, $\mathrm{ZnS}, \mathrm{SiO}_{2}, \mathrm{TiO}_{2}$ and $\mathrm{ZrO}_{2}$. Electrospray pyrolysis can be used to produce dense or hollow, porous or non-porous, coated or free, agglomerated or non-ag- 
Table 1 Methods for the preparation of nanoparticles

\begin{tabular}{|c|c|c|c|c|}
\hline Nanoparticle & Method of synthesis/microorganisms & Controlled size (nm) & Morphology & References \\
\hline \multicolumn{5}{|c|}{ Synthesis of nanoparticles by physical and chemical methods } \\
\hline $\mathrm{CuO}$ & Sonochemical synthesis & $20(\mathrm{~L}), 2(\mathrm{~W})$ & Nanocrystalline & Kumar et al. (2000) \\
\hline $\mathrm{Co}_{3} \mathrm{O}_{4}$ & Sonochemical synthesis & 30 & Nanocrystalline & Kumar et al. (2000) \\
\hline $\mathrm{PbSe}$ & $\begin{array}{l}\text { Sonochemical synthesis } \\
\text { Complexing agent_-TSC }\end{array}$ & $5-10$ & Spherical & Zhu et al. (2002) \\
\hline $\mathrm{PbSe}$ & $\begin{array}{l}\text { Sonochemical synthesis } \\
\text { Complexing agent-NTA }\end{array}$ & $20 \times 27$ & Rectangular & Zhu et al. (2002) \\
\hline $\mathrm{TiO}_{2}$ & Hydrothermal & $7-25$ & Thin film & Chae et al. (2003) \\
\hline $\mathrm{Cu}_{2} \mathrm{O}$ & Solution-phase synthesis & $200-450$ & Nanocubes & Gou and Murphy (2003) \\
\hline $\mathrm{Au}$ & One-phase synthesis & 3.5 & Crystalline & Kim et al. (2004) \\
\hline $\mathrm{YF}_{3}$ & Classical microemulsion & $6-50$ & Amorphous spheres & Lemyre and Ritcey (2005) \\
\hline $\mathrm{Cu}$ & Polyol method & 1.5 & Crystals & Park et al. (2007) \\
\hline $\mathrm{Fe}_{3} \mathrm{O}_{4}$ & Co-precipitation & 8 & Fine powders & Shen et al. (2009) \\
\hline Zno & One-step flame spray pyrolysis & $8.8-47$ & Powder & Mekasuwandumrong et al. (2010) \\
\hline $\mathrm{Ag}$ & Nucleation and growth & 30 & Spherical & García et al. (2012) \\
\hline $\mathrm{ZnS}$ & Microwave irradiation & $<7$ & Spherical & Soltani et al. (2012) \\
\hline $\mathrm{CdS}$ & Microwave irradiation & $6-16$ & Hexagonal & Soltani et al. (2012) \\
\hline $\mathrm{CeO}_{2}$ & Chemical precipitation method & 5 & Spherical & Li et al. (2012a) \\
\hline \multicolumn{5}{|c|}{ Synthesis of nanoparticles by microorganisms } \\
\hline \multirow[t]{4}{*}{$\mathrm{Ag}$} & Fusarium oxysporum & $5-15$ & Hydrosol & Ahmad et al. (2003) \\
\hline & P. brevicompactum WA 2315 & $58.35 \pm 17.88$ & Crystalline & Shaligram et al. (2009) \\
\hline & Brevebacterium casei & $10-50$ & Spherical & Kalishwaralal et al. (2010) \\
\hline & Rhodococcus sp. & 10 & Spherical & Otari et al. (2012) \\
\hline \multirow[t]{4}{*}{$\mathrm{Au}$} & Rhodopseudomonas capsulate & $10-20$ & Spherical & He et al. (2007) \\
\hline & Pseudomonos aeruginosa & $15-30$ & Spherical & Phanikrishna Sharma et al. (2009) \\
\hline & Brevebacterium casei & $10-50$ & Spherical & Kalishwaralal et al. (2010) \\
\hline & Streptomyces griseus & 50 & Spherical & Khadivi Derakhshan et al. (2012) \\
\hline
\end{tabular}

glomerated particles by controlling the process conditions and choice of reactants. The high-purity nanoparticles of metals and its oxides with engineered properties can be synthesized by flame spray pyrolysis. The solvent-containing metal precursors and oxidizing gas are sprayed into a flame; thereby, nanosized metals or its oxides are produced by combustion. The synthesis of nanoparticles using microorganisms has gained considerable attention due to their environment friendly nature, and this method has also proved to overcome the cost of the production process in a cost-effective manner. The functional properties of nanoparticles depend mainly on morphology (size, shape external and internal core structure) and its chemical composition. The reaction kinetics need to be controlled and optimized for appropriate applications (Choi et al. 2001). Nanoparticles synthesized by physical, chemical and biological methods exhibit improved properties during photocatalytic reactions in the degradation of organic and inorganic pollutants, but it has some disadvantages such as poor absorption of visible light radiation and rapid recombination of photogenerated electron/hole pairs. These disadvantages can be overcome by the nanocomposites (Table 1).

\section{Synthesis of nanocomposites}

Nanocomposites are prepared by the combination of two or more materials among which one of the materials is of nanoscale. Nanocomposites can be classified into three categories based on its core constituents: ceramic matrices nanocomposites-CMNCs $\left(\mathrm{Al}_{2} \mathrm{O}_{3} / \mathrm{SiO}_{2}, \mathrm{SiO}_{2} / \mathrm{Ni}, \mathrm{Al}_{2} \mathrm{O}_{3} /\right.$ $\mathrm{TiO}_{2}$ and $\mathrm{Al}_{2} \mathrm{O}_{3} / \mathrm{CNT}$ ), polymer matrices nanocomposites-PMNCs (polyester/TiO 2 , polymer/CNT and polymer/ silicates) and metal matrices nanocomposites-MMNCs $\left(\mathrm{Ni} / \mathrm{Al}_{2} \mathrm{O}_{3}, \mathrm{Co} / \mathrm{Cr}, \mathrm{Fe} / \mathrm{MgO}\right.$ and $\left.\mathrm{Al} / \mathrm{CNT}\right)$. CMNCs are prepared by polymer precursor process, powder process and by sol-gel process. Sol-gel process is relatively simple 
Table 2 Methods for the preparation of Nanocomposites

\begin{tabular}{|c|c|c|c|c|}
\hline Nanocomposites & Method of synthesis & Properties and process efficiency & Application & References \\
\hline \multicolumn{5}{|c|}{ Synthesis of nanocomposites by physical and chemical methods } \\
\hline $\mathrm{ZnO} / \mathrm{SnO}_{2}$ & Co-precipitation method & $\begin{array}{l}\text { Photodegradation efficiency was twice than } \\
\text { that of individual nanoparticles due to } \\
\text { heterojunction effect }\end{array}$ & $\begin{array}{l}\text { Degradation of } \\
\text { methyl orange }\end{array}$ & $\begin{array}{l}\text { Zhang et al. } \\
\text { (2005) }\end{array}$ \\
\hline $\mathrm{TiO}_{2} /$ montmorillonite & Heterocoagulation & $\begin{array}{l}\text { Significant increase in the photocatalytic } \\
\text { efficiency of } \mathrm{TiO}_{2} \text { by intercalation in } \\
\text { montmorillonite support }\end{array}$ & $\begin{array}{l}\text { Photooxidation of } \\
\text { phenol }\end{array}$ & $\begin{array}{l}\text { Kun et al. } \\
\text { (2006) }\end{array}$ \\
\hline $\mathrm{Ag} / \mathrm{TiO}_{2}$ & Vapor-thermal method & $\begin{array}{l}\text { Exhibits recyclable photocatalytic activity } \\
\text { and can be readily separated from the } \\
\text { treated solution by natural settlement }\end{array}$ & $\begin{array}{l}\text { Degradation of } \\
\text { rhodamine B }\end{array}$ & $\begin{array}{l}\text { Cheng et al. } \\
\text { (2010) }\end{array}$ \\
\hline $\mathrm{SnS}_{2} / \mathrm{TiO}_{2}$ & Solvothermal treatment & $\begin{array}{l}\text { Exhibits highest photocatalytic activity and } \\
\text { good photocatalytic stability }\end{array}$ & Reduction in $\mathrm{Cr}(\mathrm{VI})$ & Li et al. (2012b) \\
\hline $\mathrm{TiO}_{2} /$ carbon & Sol-gel method & $\begin{array}{l}\text { Enhanced photocatalytic activity the synergic } \\
\text { effect between } \mathrm{TiO}_{2} \text { and carbon }\end{array}$ & $\begin{array}{l}\text { Degradation of RB- } \\
19 \text { dye }\end{array}$ & $\begin{array}{l}\text { da Costa et al. } \\
\text { (2012) }\end{array}$ \\
\hline $\begin{array}{l}\text { Graphene/TiO } / \\
\mathrm{Fe}_{3} \mathrm{O}_{4}\end{array}$ & $\begin{array}{l}\text { Chemical precipitation } \\
\text { method }\end{array}$ & $\begin{array}{l}\text { Recollectable and stable photocatalyst and is } \\
\text { able to degrade dyes under sunlight }\end{array}$ & $\begin{array}{r}\text { Degradation of } \\
\text { organic dyes }\end{array}$ & Lin et al. (2012) \\
\hline Starch/polyaniline & $\begin{array}{l}\text { Chemical oxidative } \\
\text { polymerization of aniline }\end{array}$ & $\begin{array}{l}\text { Acts as a effective adsorbent for the removal } \\
\text { of dyes from textile effluents }\end{array}$ & $\begin{array}{l}\text { Removal of reactive } \\
\text { dyes }\end{array}$ & $\begin{array}{l}\text { Janaki et al. } \\
\quad(2012)\end{array}$ \\
\hline $\mathrm{ZnO} / \mathrm{MgO}$ & Electrochemical method & $\begin{array}{l}\text { Consists of more defects and vacancies and } \\
\text { exhibits high photocatalytic degradation }\end{array}$ & $\begin{array}{l}\text { Degradation of } \\
\text { eosin yellow }\end{array}$ & $\begin{array}{l}\text { Lakshmi et al. } \\
\qquad(2012)\end{array}$ \\
\hline $\mathrm{ZnO} / \mathrm{Al}_{2} \mathrm{O}_{3}$ & Precipitation method & $\begin{array}{l}\text { Acts as a good adsorbent and exhibits high } \\
\text { surface area with active surface charge }\end{array}$ & $\begin{array}{l}\text { Removal of methyl } \\
\text { orange }\end{array}$ & $\begin{array}{l}\text { Tajizadegan } \\
\text { et al. (2013) }\end{array}$ \\
\hline $\mathrm{BaTiO}_{3} /$ graphene & $\begin{array}{l}\text { One-pot hydrothermal } \\
\text { method }\end{array}$ & $\begin{array}{l}\text { The photosensitization process induces } \\
\text { visible light photocatalytic activity by } \\
\text { transforming the band gap }\end{array}$ & $\begin{array}{l}\text { Degradation of } \\
\text { methylene blue }\end{array}$ & $\begin{array}{l}\text { Wang et al. } \\
\text { (2015) }\end{array}$ \\
\hline
\end{tabular}

and produces high-purity nanomaterials with high chemical homogeneity. It is also applied for the synthesis of composites with liquids or with viscous fluids. (Camargo et al. 2009). Among PMNCs, natural polymers such as chitosan, cellulose fibers, arabic gum, gellan gum and guar gum are used to prepare nanocomposites with metals because of its adsorbing property which attracts the pollutants close to the vicinity of reaction site. MMNCs prepared using nanosized metals or oxides of silver nanoparticles (nano as sorbents), ferric, manganese, titanium, copper and cerium, which provides high surface area with specific affinity (Fabrega et al. 2011; Feng et al. 2012; Gupta et al. 2011). These composites are synthesized by spray pyrolysis, liquid infiltration, rapid solidification method and ball milling. From the existing literature, it was observed that MMNCs have wide application in effluent treatment. Temperature plays a major role during the synthesis of nanocomposites. Crystalline size of the material and its structural properties depends on the annealing temperature employed during the synthesis of nanocomposite by spin coating technique. Experimental studies show that crystalline phase of the nanocomposite increases with increase in the annealing temperature up to $550{ }^{\circ} \mathrm{C}$ at optimum preheating temperature of $275^{\circ} \mathrm{C}$ (Habibi and Sheibani 2010). Process temperature not only affects the structural properties of the nanocomposites, but also affects the dimensional stability of the nanomaterial employed during the synthesis process. Enhancement in the dimensional stability of the nanoparticle results in improved electrochemical performance of the synthesized nanocomposite ( $\mathrm{Ng}$ et al. 2006). In Table 2, synthesis, properties of MMNCs and their application on degrading xenobiotics explored by researchers were listed.

\section{Novel nanostructures}

Morphological properties of the nanomaterials play a vital role in determining the photocatalytic efficiency as they have a great influence on their optoelectronic properties. Thus, the photodegradation efficiency of various nanostructures has been discussed below (Fig. 4).

\section{Carbon nanostructures (CNFs and CNTs)}

Use of carbon nanostructures such as carbon nanofibers (CNFs) and nanotubes (CNTs) in photocatalytic removal of pollutants has gained great interest due to the adsorption capacity of the carbonaceous materials (Pant et al. 2013). In addition, CNFs efficiently capture and transport 
Fig. 4 SEM images of novel nanostructures from reported literatures

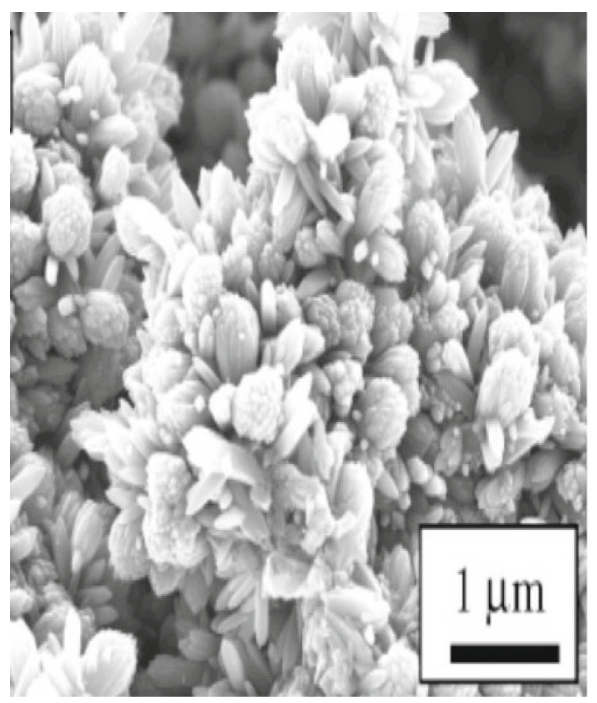

SEM Image of Nano Flowers

(Lui et al. 2013)

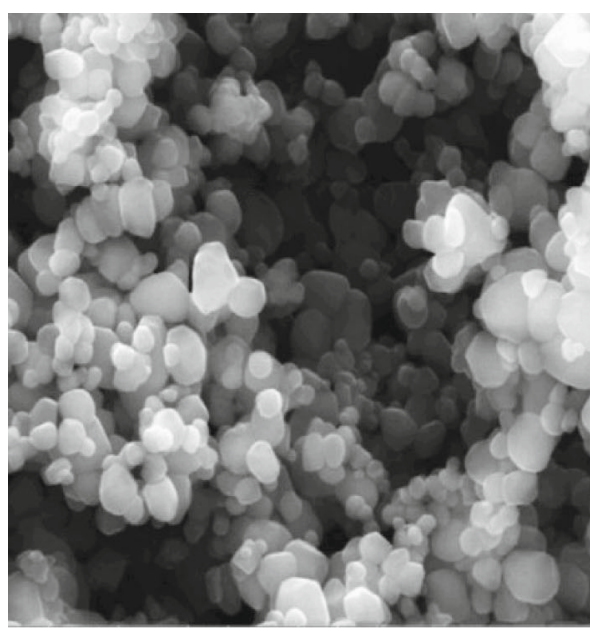

SEM Image of Nano Cones

(Sangari et al. 2015)

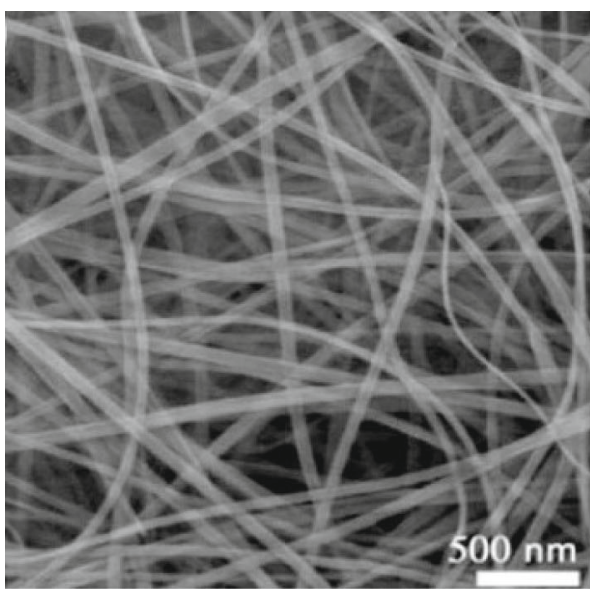

SEM Image of Nano Ribbons

(Cao et al. 2014)

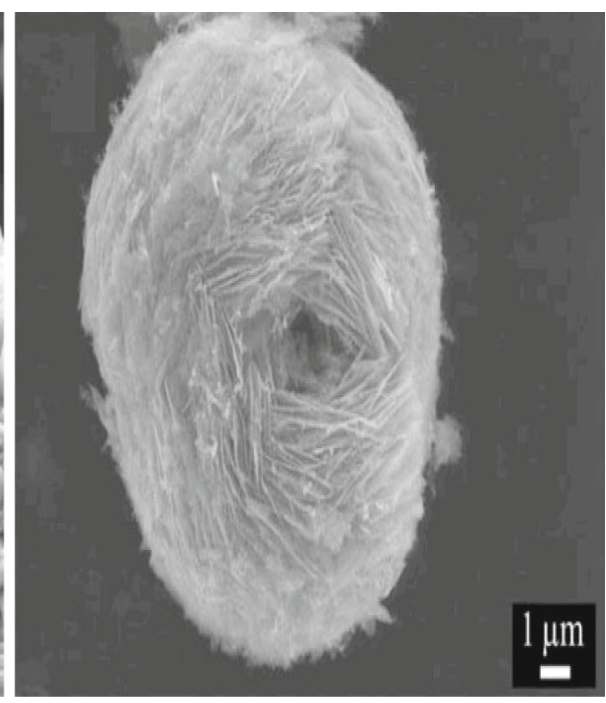

SEM Image of Nano flakes (Ong et al. 2013)

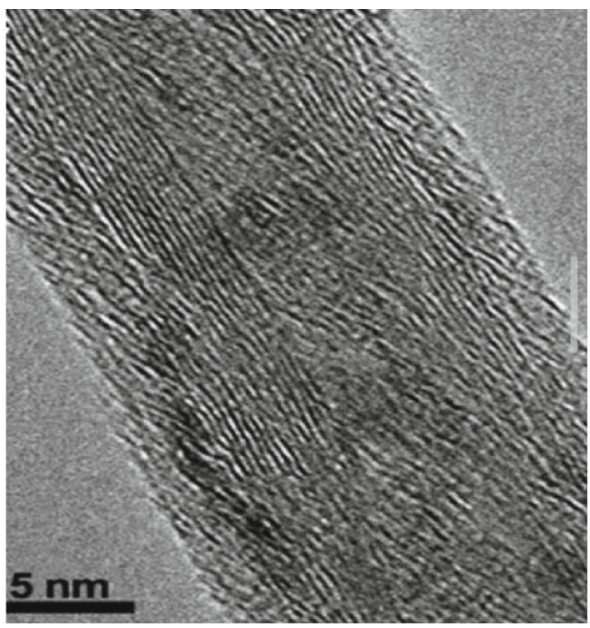

SEM Image of Carbon nanotubes (Woan et al. 2009)

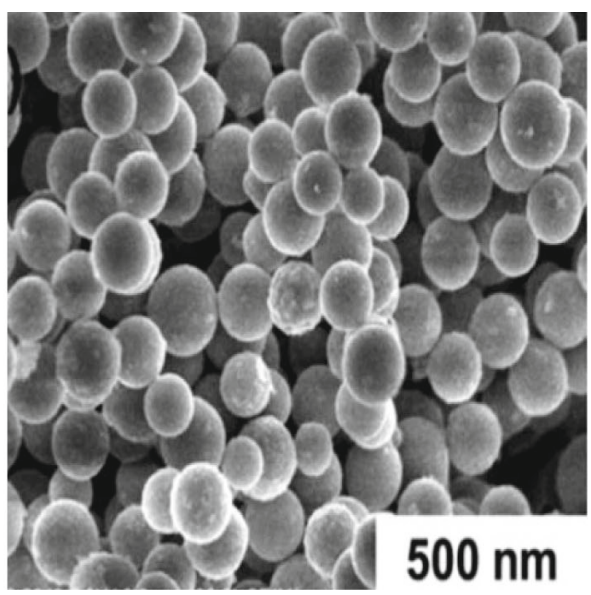

SEM Image of Nano Spheres (Qin et al. 2014) 
photogenerated electrons through highly conductive long CNFs, thereby preventing recombination and enhancing the photocatalytic activity (Kim and Park 2011). The combined activity of the activated carbon and nanocomposites shows a synergistic effect on the efficient degradation of pollutants due to the enhancement of pollutant adsorption that is attributed to the increase in surface area of the nanostructure (Pant et al. 2013). In general, these carbon nanostructures are synthesized by electrospinning method followed by calcination and hydrothermal treatment.

\section{Hierarchical porous materials}

Hierarchically structured nanocomposites, as improved catalysts, are nanocomposites having high surface area, larger pore volume, tunable pore size and higher-temperature stability (Ong et al. 2013). The photocatalytic efficiency of nano- (or) mesoporous materials increases due to the band alignment, multiple reflections and scattering of incident (UV) light. In addition, the porous networks in these hierarchical nanocomposites act as route for light transfer as well as mass transfer. Among the existing growth deposition techniques, the "chemical bath deposition" approach is preferred for the synthesis of secondorder branched structures on primary nanostructures due to excellent control over the structure, morphology and dimensions of the obtained branches. The formation of hierarchical structure is generally considered to be a selfassembly process. These self-assembled materials may be of different morphological structures such as nanoflowers, nanocones, nanoribbons and nanospheres.

\section{Nanoflowers}

The enhanced photocatalytic activity of nanoflowers results from the larger content of oxygen vacancy on the surface of the nanomaterials which acts as the active reaction centers by capturing the photoinduced electrons, thereby preventing the recombination. Further composting of the nanoflowers with suitable semiconductor nanomaterial will promote the photocatalytic activity. One-pot approach is employed for the synthesis of nanoflowers, and doping of different nanomaterials on the surface of the as-synthesized nanoflowers is done by hydrothermal techniques (Cao et al. 2008; Yuan et al. 2010). The morphology-dependent enhancement in the properties of nanoflowers helps in overcoming the limitation of recombination. Wang et al. (2008b) studied the photocatalytic degradation of 4-chlorophenol (4-CP) in aqueous solution by $\mathrm{ZnO}$ nanoflowers.

\section{Nanoribbons}

One-pot hydrothermal reaction followed by calcination yields nanoribbons of length ranging from few nanometers to several tens of micrometers. Acid washing process of the precipitate obtained from hydrothermal reaction is essential for the synthesis of nanoribbons. This controlled synthesis generates nanoribbons of large surface area with interiors rich in pores having enhanced optical properties. Homogeneous distribution of other nanoparticles on the surface of nanoribbbons not only increases the optical adsorption efficiency but also facilitates the separation of photogenerated charges. Cao and Xue (2010) reported the enhanced photocatalytic degradation of salicylic acid, rhodamine $\mathrm{B}$ and methyl orange by $\mathrm{TiO}_{2}$ nanoribbons.

\section{Nanocones}

These nanocones can be synthesized by low-temperature simple solution process (Chauhan et al. 2011), homogenous precipitation (Ma et al. 2014) and surfactant-free solvothermal method (Jia et al. 2009). The morphological changes induced by the doping nanocones with other nanoparticles exhibit higher photocatalytic activity when compared to homogenous nanocones (Chauhan et al. 2011; Ma et al. 2014). The enhanced photocatalytic activity of nanocones is attributed to the increased light absorption efficiency and creation of oxygen vacancies which increases the concentration of $\mathrm{OH}$ radicals. Sangari et al. (2015) studied the photocatalytic activity of fluorine-doped $\mathrm{TiO}_{2}$-carbon nanocones in the degradation of methyl orange under UV irradiation $(254 \mathrm{~nm})$ and visible light irradiation.

\section{Nanospheres}

The enhanced photocatalytic efficiency of nanospheres is attributed to their increased pollutant absorption affinity, optical absorption and efficient charge transfer. These nanospheres can be synthesized by solvothermal methods (Li et al. 2007), Stober and seed-mediated method (Hirakawa and Kamat 2005) or by lyophilization technique followed by thermal treatment (Zhang et al. 2013). Wrapping of the nanospheres with materials such as graphene (Zhang et al. 2013) and silver (Zhang et al. 2010) will prevent the aggregation of nanospheres causing significant enhancement in photodegradation. Qin et al. reported the visible light-driven photocatalytic degradation of chromium and organic dyes by $\mathrm{Bi}_{2} \mathrm{O}_{3}$ porous nanospheres ( $\mathrm{Qin}$ et al. 2014). 


\section{Nanoflakes}

Nanoflakes are a special class of nanomaterials that are characterized to possess high photocatalytic activity under visible light irradiation when compared to their pure form nanoparticles due to the changes in optoelectronic properties (Tang et al. 2012; Zhang et al. 2011) These nanoflakes can be prepared by alkaline or at low-temperature hydrothermal techniques. Ong et al. (2013) reported the photocatalytic degradation of methyl orange by metalloaded ZnO nanoflakes. Tang et al. (2012) reported the improved photocatalytic degradation of methyl orange and bisphenol by hierarchical $\mathrm{TiO}_{2}$ nanoflakes.

\section{Application of nanocomposites in removal of recalcitrant}

\section{Removal of heavy metals}

Industrial effluents contain both organic and inorganic pollutants. The major inorganic pollutants are toxic heavy metals such as $\mathrm{Cr}(\mathrm{VI}), \mathrm{Pb}, \mathrm{Cd}, \mathrm{Cu}, \mathrm{Ni}, \mathrm{Mn}$ and $\mathrm{Zn}$ which have become a serious threat to aquatic life due to their non-biodegradable, toxic nature and detrimental to human health via food chain. Major sources of heavy metals are chrome plating, electronic, metallurgical, timber and leather tanning industries. The presence of such heavy metals in water is a serious risk factor for the environment and must be converted into their reduced form before discharging directly into the sewer. Recent studies proved that the use of nanoparticles for the reduction in heavy metals is very effective and most promising technology (Aarthi and Madras 2008; Banerjee et al. 2012). Reduction in $\mathrm{Cr}^{6+}$ ion increases with increase in photocatalyst dosage and decreases in $\mathrm{pH}$ due to increased deposition of $\mathrm{Cr}(\mathrm{OH})_{3}$ on the surface of $\mathrm{TiO}_{2}$ (Naimi-Joubani et al. 2015; Shirzad Siboni et al. 2012), anionic-type adsorption of Cr(VI) onto the catalyst surface and increased potential difference between the conduction band of $\mathrm{TiO}_{2}$ and $\mathrm{Cr}(\mathrm{VI})$ (Yang et al. 2012). The degradation efficiency of $\mathrm{Cr}(\mathrm{VI})$ under UV light using three different composites is compared. $\mathrm{TiO}_{2} /$ reduced graphene oxide composite degrades $91 \%$ of $\mathrm{Cr}^{6+}$ ion into non-toxic form in $250 \mathrm{~min}$ (Liu et al. 2011). When $\mathrm{TiO}_{2}$ is combined with diatomite, $100 \%$ degradation of $\mathrm{Cr}(\mathrm{VI})$ is achieved within $150 \mathrm{~min}$ due to their enhanced adsorption capacity (Sun et al. 2014). $\mathrm{TiO}_{2} / \mathrm{ZnO}$ composite shows excellent photocatalytic performance in the reduction in $\mathrm{Cr}(\mathrm{VI})$ than other two composites with complete reduction in $\mathrm{Cr}(\mathrm{VI})$ in 60 min under UV irradiation (Naimi-Joubani et al. 2015).

\section{Degradation of textile dyes}

Release of colored wastewaters in the environment is toxic and carcinogenic and poses severe threats to microorganisms, aquatic lives and human beings. About $1-20 \%$ of total world production of dyes is lost during dying process and released into the environment. Reactive dyes bearing azo group $(-\mathrm{N}=\mathrm{N}-)$ as a chromophore are the widely used synthetic colorants in textile industries which is well known for their recalcitrant and acute toxicity. Nanophotocatalysis is one of the most economical and ecofriendly method for the remediation of toxic textile dyes. Degradation of azo dyes using $\mathrm{TiO}_{2}$ and $\mathrm{ZnO}$ composites synthesized via chemical methods is highly efficient than pure $\mathrm{TiO}_{2}$ and $\mathrm{ZnO}$ nanoparticles (Sun et al. 2002; Zhang and Zeng 2010). Rate of degradation of dyes is highly affected by the type of composite used. ZnO/ZTO nanocomposite shows $95 \%$ degradation of methyl orange (MO) in $3 \mathrm{~h}$ under UV light, and the degradation time is reduced to $2 \mathrm{~h}$ when $\mathrm{ZnO} / \mathrm{ZnS}$ composite is used as a photocatalyst (Danwittayakul et al. 2013; $\mathrm{Li}$ et al. 2013). $\mathrm{TiO}_{2} /$ diatomite composite shows $90 \%$ degradation of $\mathrm{MO}$ in 90 min under UV light. If $\mathrm{ZnO}$ nanoparticle is combined with $\mathrm{TiO}_{2}$ instead of diatomite, $87.68 \%$ degradation of $\mathrm{MO}$ is achieved in 60 min under UV irradiation (Ge et al. 2009; $\mathrm{Xia}$ et al. 2014). Among these four nanocomposites, $\mathrm{ZnO} /$ $\mathrm{TiO}_{2}$ composite holds best for the degradation of methyl orange.

\section{Degradation of pesticides}

Pesticides belong to the family of biocide and most commonly used in agricultural practices for pest control. Migration of pesticides to ground water and surface water is hazardous to aquatic and human lives and is considered toxic, bioaccumulative and carcinogenic in nature. Various conventional methods have been employed to destroy these chemicals, but the pesticides are not degraded completely; instead, these methods transform the phase of the pollutants (Phanikrishna Sharma et al. 2010). Nanophotocatalysis proved to be an efficient technology for the treatment of water contaminated by pesticides. The usage of nanocomposites instead of individual nanoparticles has shown enhanced photocatalytic performance in the degradation of pesticides (Xiaodan et al. 2006). Percentage of degradation increases with increase in substrate concentration (Jonidi-Jafari et al. 2015), and it also depends on type of composite used. $\mathrm{TiO}_{2} / \mathrm{ZnO}$ nanocomposite proves to be highly efficient and best for the degradation of $\mathrm{MO}$ and $\mathrm{Cr}(\mathrm{VI})$, but when this composite is used for the degradation of diazinon, the degradation efficiency in 
120 min is only $87.16 \%$ under UV irradiation (Jonidi-Jafari et al. 2015). The maximum degradation $(96.3 \%)$ of diazinon is obtained by using LED-activated $\mathrm{FeFNS} / \mathrm{TiO}_{2}$ composite at the reaction time of $100 \mathrm{~min}$ due to the production of large number of free $\mathrm{OH}$ radicals during the time of degradation (Hossaini et al. 2014) (Table 3).

\section{Nanophotocatalytic reactors}

In spite of extensive research on nanophotocatalytic materials for the degradation of pollutants, transfer of technology for real-time application in industries is very less because of the lack of optimized steady-state methodologies in scaling up the process. As reported in the literature, photocatalytic reactors are mainly classified into two types as slurry and immobilized photoreactor. In the former, nanoparticles are suspended in the medium, and in the later nanoparticles are fixed on the solid matrices. Though the application of wastewater treatment is based on slurry-type reactors, the release of nanoparticles into the water streams makes immobilized reactors more suitable for the continuous process ( $\mathrm{Li}$ et al. 2014). Many research works have been reported in immobilizing the nanoparticles onto solid matrices ( $\mathrm{Li}$ et al. 2012c; Wang et al. 2012; Zhang et al. 1994). Photon conversion efficiency and mass transfer (Chan et al. 2003; Shankar et al. 2004) are the two important properties to be considered for the reactor design. The complex physical and chemical phenomena are involved in the interactions between the photons, catalyst and reactants which make modeling difficult. The interpretation from kinetic parameters generated using nanophotocatalytic reactions is difficult because they are generated using reactors (reactions) of different dimensions, different rheological properties and different operating conditions (Grcic and Li Puma 2013). The degradation of water contaminants in reactors can be modeled through the development of simple mathematical tools which concentrates much on transfer of photons and reactor dimensions. Researchers have developed models based on absorption scattering model of two-flux and sixflux theories. Dual slant-placed electrodes thin-film PC reactor (Xu et al. 2013), solar PC thin-film cascade reactor (Chan et al. 2003), dual rotating disk PC reactor (Shankar et al. 2004), thin-film photoelectrocatalytic reactor (Xu et al. 2009) and spinning disk reactor (Boiarkina et al. 2013) have been developed in the recent years for the degradation of industrial pollutants. Though the

Table 3 Removal of recalcitrant by nanocomposites

\begin{tabular}{|c|c|c|c|c|c|}
\hline Catalyst & Pollutant & Substrate conc. & $\begin{array}{l}\text { Reaction } \\
\text { kinetics }\end{array}$ & Rate constant & References \\
\hline \multicolumn{6}{|l|}{ Removal of metals } \\
\hline $\begin{array}{l}\text { Poly(acrylamide) modified } \\
\text { guar gum-silica }\end{array}$ & $\mathrm{Cd} 2+$ & $500 \mathrm{mg} \mathrm{L}^{-1}$ & $\begin{array}{l}\text { Pseudo-second } \\
\text { order }\end{array}$ & $2.85 \times 10^{-3} \mathrm{mg}^{-1} \mathrm{~min}^{-1}$ & Singh et al. (2009) \\
\hline $\begin{array}{l}\text { Poly(acrylamide) modified } \\
\text { guar gum-silica }\end{array}$ & $\mathrm{Cd} 2+$ & $700 \mathrm{mg} \mathrm{L}^{-1}$ & $\begin{array}{l}\text { Pseudo-second } \\
\text { order }\end{array}$ & $1.88 \times 10^{-4} \mathrm{mg}^{-1} \mathrm{~min}^{-1}$ & Singh et al. (2009) \\
\hline $\begin{array}{l}\mathrm{Fe}_{3} \mathrm{O}_{4} / \text { cyclodextrin } \\
\text { polymer }\end{array}$ & $\mathrm{Pb} 2+$ & $3 \times 10^{5} \mathrm{mg} \mathrm{L}^{-1}$ & $\begin{array}{l}\text { Pseudo-second } \\
\text { order }\end{array}$ & $0.003 \mathrm{~g} \mathrm{mg}^{-1} \mathrm{~min}^{-1}$ & $\begin{array}{l}\text { Badruddoza et al. } \\
\text { (2013) }\end{array}$ \\
\hline $\begin{array}{l}\mathrm{Fe}_{3} \mathrm{O}_{4} / \text { cyclodextrin } \\
\text { polymer }\end{array}$ & $\mathrm{Ni} 2+$ & $3 \times 10_{5} \mathrm{mg} \mathrm{L}^{-1}$ & $\begin{array}{l}\text { Pseudo-second } \\
\text { order }\end{array}$ & $0.033 \mathrm{~g} \mathrm{mg}^{-1} \mathrm{~min}^{-1}$ & \\
\hline \multicolumn{6}{|l|}{ Degradation of textile dyes } \\
\hline $\mathrm{TiO}_{2}-\mathrm{RGO}$ & Rhodamine B & $2 \times 10^{-5} \mathrm{M}$ & $\begin{array}{l}\text { Pseudo-first } \\
\text { order }\end{array}$ & $0.031 \mathrm{~min}^{-1}$ & $\begin{array}{l}\text { Sher Shah et al. } \\
\text { (2012) }\end{array}$ \\
\hline $\mathrm{PANI} / \mathrm{ZnO}$ & Methylene Blue & $10^{-5} \mathrm{M}$ & $\begin{array}{l}\text { Pseudo-first } \\
\text { order }\end{array}$ & $0.011 \mathrm{~min}^{-1}$ & $\begin{array}{l}\text { Eskizeybek et al. } \\
\text { (2012) }\end{array}$ \\
\hline $\mathrm{PANI} / \mathrm{ZnO}$ & Malachite Green & $10^{-6} \mathrm{M}$ & $\begin{array}{l}\text { Pseudo-first } \\
\text { order }\end{array}$ & $0.02200 \mathrm{~min}^{-1}$ & \\
\hline $\mathrm{Au}-\mathrm{TiO}_{2}$ & Acid Red 88 & $5 \times 10^{-5} \mathrm{M}$ & First order & $3.8 \times 10^{-4} \mathrm{~s}^{-1}$ & $\begin{array}{l}\text { Sathish Kumar et al. } \\
\text { (2008) }\end{array}$ \\
\hline \multicolumn{6}{|l|}{ Degradation of pesticides } \\
\hline $\mathrm{TiO}_{2} / \mathrm{PNS}$ & Isoproturon & $5 \mathrm{~g}$ & $\begin{array}{l}\text { Pseudo-first } \\
\text { order }\end{array}$ & $0.0788 \mathrm{~min}^{-1}$ & $\begin{array}{l}\text { Phanikrishna Sharma } \\
\text { et al. (2009) }\end{array}$ \\
\hline NZNC & Metaldehyde & $28 \mathrm{~g}$ & First order & $0.0363 \mathrm{~min}^{-1}$ & Doria et al. (2013) \\
\hline $\mathrm{TiO}_{2} /$ silica gel & $\begin{array}{l}\text { Organophosphate and } \\
\text { phosphoglycine }\end{array}$ & $14 \mathrm{~g}$ & First order & $0.031 \mathrm{~min}^{-1}$ & Echavia et al. (2009) \\
\hline
\end{tabular}


development of reactors has been explored in various dimensions, the mass transfer limitations are yet to overcome.

\section{Challenges and future perspectives}

\section{Novel reactors}

The extensive research works in the usage of nanoparticles as a catalyst in nanophotocatalysis have led to the development in designing the reactors with the optimized steady-state process parameters. The key challenges in the process intensification are maximum utilization of photons and mass transfer limitations. The usage of nanocomposites in overcoming the problem of electron/hole pair recombination can be extended by incorporating nanocomposites into the nanophotocatalytic reactor systems. The nextgeneration reactors are microfluidic reactors which open a wide platform for intense research aspects in both synthesis and reaction phase. Microfluidic reactors are reactors which handle reactants in a microvolume. The major characteristics of microreactors are high surface-to-volume ratio, increased effect of diffusion and advection causing high mass transfer coefficient, stable hydrodynamics, low Reynold's flow and mixing, and easy controllability which makes them an superior option over conventional reactors. Recently, microfluidics reactors have been employed for the synthesis of various nanoparticles including chitosanbased nanoparticles (Majedi et al. 2012) and PLGA-based nanoparticles (Song et al. 2008). Developing microfluidic reactors with appropriate sensors for monitoring and controlling the handling and synthesis of nanoparticles will be a promising area of research. Hence, it is evident that there is a wide scope in extending these microfluidic reactors for the effective synthesis of nanocomposites and its application in wastewater treatment.

\section{Novel structures of nanocomposites}

The preparation of novel structures (nanoflowers, nanorods, nanocones, nanospheres and nanoflakes) with improved structural and functional properties such as optoelectronic, adsorptive forces and potential charge transfer opened a wide area of research platform. The various structures of nanoparticles with desired properties could be synthesized by the controlled synthesis methods.

\section{Composition of nanocomposites}

The potential of nanocomposites prepared using $\mathrm{TiO}_{2}, \mathrm{ZnO}$ and ZTO was explored well in the past three decades for the removal of water pollutants to great extent. But the composites prepared using ceramic and polymer matrices are still in the primitive stage. This could be one of the frontier areas in nanophotocatalysis as it could generate novel composites with enhanced properties.

\section{Conclusion}

In this review, nanophotocatalysis an advanced oxidation process (AOP) has been discussed. In nanophotocatalysis, the photoreaction is accelerated by the irradiation of catalyst. They have shown efficient degradation of recalcitrants in water system. The review classifies and discusses about the various methods of synthesis of nanoparticles which has been used in the treatment of effluents. Nanoparticles have improved properties such as large surface-to-volume ratio, controlled uniform particle size and its composition which enhances the degradation rate. But, nanoparticles cause recombination of holes and electron pair which is a severe drawback. This drawback of nanoparticles can be overcome by combining two or more nanoparticles forming nanocomposites. Nanocomposites are capable of decreasing the rate of recombination, leading to effective degradation of individual pollutants because of their enhanced optoelectronic, functional and structural properties. From the literature, it is observed that nanophotocatalytic process for wastewater treatment has employed nanocomposites possessing titanium dioxide $\left(\mathrm{TiO}_{2}\right)$ and zinc oxide $(\mathrm{ZnO})$ as their core component. This review discusses elaborately the various methods for the synthesis of nanocomposites and various structures obtained by them. The usage of nanocomposites for degrading dyes, pesticides and metals are increasing significantly day by day. The treatment of dyes, pesticides and metals using nanocomposites has been tabulated and discussed based on their degradation efficiency and reaction kinetics. The review also provides an insight about the various reactors used so far in treating effluents using nanocomposites. After extensive review of various research findings about nanocomposites for effluent treatment, it was inferred that modified nanostructures, core composition of nanocomposites, modified and novel reactors have wide scope in future.

Acknowledgments The authors are thankful to Tamil Nadu State Council for Science and Technology, India, for providing an opportunity to do collaborative research through Young Scientist fellowship.

\section{References}

Aarthi T, Madras G (2008) Photocatalytic reduction of metals in presence of combustion synthesized nano- $\mathrm{TiO}_{2}$. Catal Commun 9:630-634. doi:10.1016/j.catcom.2007.07.001 
Ahmad A, Mukherjee P, Senapati S, Mandal D, Khan MI, Kumar R, Sastry M (2003) Extracellular biosynthesis of silver nanoparticles using the fungus Fusarium oxysporum. Colloids Surf B 28:313-318. doi:10.1016/S0927-7765(02)00174-1

Akpan UG, Hameed BH (2009) Parameters affecting the photocatalytic degradation of dyes using $\mathrm{TiO}_{2}$-based photocatalysts: a review. J Hazard Mater 170:520-529. doi:10.1016/j.jhazmat. 2009.05.039

Badruddoza AZM, Shawon ZBZ, Tay WJD, Hidajat K, Uddin MS (2013) $\mathrm{Fe}_{3} \mathrm{O}_{4} /$ cyclodextrin polymer nanocomposites for selective heavy metals removal from industrial wastewater. Carbohydr Polym 91:322-332. doi:10.1016/j.carbpol.2012.08.030

Banerjee P, Chakrabarti S, Maitra S, Dutta BK (2012) Zinc oxide nano-particles-sonochemical synthesis, characterization and application for photo-remediation of heavy metal. Ultrason Sonochem 19:85-93. doi:10.1016/j.ultsonch.2011.05.007

Boiarkina I, Norris S, Patterson DA (2013) The case for the photocatalytic spinning disc reactor as a process intensification technology: comparison to an annular reactor for the degradation of methylene blue. Chem Eng J 225:752-765

Camargo PHC, Satyanarayana KG, Wypych F (2009) Nanocomposites: synthesis, structure, properties and new application opportunities. Mater Res 12:1-39

Cao X, Xue X (2010) Heterostructured Ag@ $\mathrm{TiO}_{2}$ nanoribbons: synthesis, characterization, and photocatalytic activity. Sci Adv Mater 2:390-395

Cao F, Shi W, Zhao L, Song S, Yang J, Lei Y, Zhang H (2008) Hydrothermal synthesis and high photocatalytic activity of 3D wurtzite $\mathrm{ZnSe}$ hierarchical nanostructures. J Phys Chem C 112:17095-17101

Cao X, Lu Z, Zhu L, Yang L, Gu L, Cai L, Chen J (2014) A new family of sunlight-driven bifunctional photocatalysts based on $\mathrm{TiO}_{2}$ nanoribbon frameworks and bismuth oxohalide nanoplates. Nanoscale 6:1434-1444

Chae SY, Park MK, Lee SK, Kim TY, Kim SK, Lee WI (2003) Preparation of size-controlled $\mathrm{TiO}_{2}$ nanoparticles and derivation of optically transparent photocatalytic films. Chem Mater 15:3326-3331

Chan AH, Chan CK, Barford JP, Porter JF (2003) Solar photocatalytic thin film cascade reactor for treatment of benzoic acid containing wastewater. Water Res 37:1125-1135

Chauhan $\mathrm{M}$ et al (2011) Utilization of $\mathrm{ZnO}$ nanocones for the photocatalytic degradation of acridine orange. J Nanosci Nanotechnol 11:4061-4066

Cheng B, Le Y, Yu J (2010) Preparation and enhanced photocatalytic activity of $\mathrm{Ag} @ \mathrm{TiO}_{2}$ core-shell nanocomposite nanowires. J Hazard Mater 177:971-977. doi:10.1016/j.jhazmat.2010.01. 013

Choi C-J, Dong X-L, Kim B-K (2001) Microstructure and magnetic properties of $\mathrm{Fe}$ nanoparticles synthesized by chemical vapor condensation. Mater Trans 42:2046-2049

da Costa E, Zamora PP, Zarbin AJ (2012) Novel $\mathrm{TiO}_{2} / \mathrm{C}$ nanocomposites: synthesis, characterization, and application as a photocatalyst for the degradation of organic pollutants. J Colloid Interface Sci 368:121-127

Danwittayakul S, Jaisai M, Koottatep T, Dutta J (2013) Enhancement of photocatalytic degradation of methyl orange by supported zinc oxide nanorods/zinc stannate $(\mathrm{ZnO} / \mathrm{ZTO})$ on porous substrates. Ind Eng Chem Res 52:13629-13636

Doria FC, Borges A, Kim J, Nathan A, Joo J, Campos L (2013) Removal of metaldehyde through photocatalytic reactions using nano-sized zinc oxide composites water. Air Soil Pollut 224:1-9

Echavia GRM, Matzusawa F, Negishi N (2009) Photocatalytic degradation of organophosphate and phosphonoglycine pesti- cides using $\mathrm{TiO}_{2}$ immobilized on silica gel. Chemosphere 76:595-600. doi:10.1016/j.chemosphere.2009.04.055

Eskizeybek V, Sarı F, Gülce H, Gülce A, Avc1 A (2012) Preparation of the new polyaniline/ZnO nanocomposite and its photocatalytic activity for degradation of methylene blue and malachite green dyes under UV and natural sun lights irradiations. Appl Catal B 119-120:197-206. doi:10.1016/j.apcatb.2012.02.034

Fabrega J, Luoma SN, Tyler CR, Galloway TS, Lead JR (2011) Silver nanoparticles: behaviour and effects in the aquatic environment. Environ Int 37:517-531

Feng L, Cao M, Ma X, Zhu Y, Hu C (2012) Superparamagnetic highsurface-area $\mathrm{Fe}_{3} \mathrm{O}_{4}$ nanoparticles as adsorbents for arsenic removal. J Hazard Mater 217:439-446

Gad-Allah TA, Fujimura K, Kato S, Satokawa S, Kojima T (2008) Preparation and characterization of magnetically separable photocatalyst $\left(\mathrm{TiO}_{2} / \mathrm{SiO}_{2} / \mathrm{Fe}_{3} \mathrm{O}_{4}\right)$ : effect of carbon coating and calcination temperature. J Hazard Mater 154:572-577. doi:10. 1016/j.jhazmat.2007.10.068

García A et al (2012) Effect of cerium dioxide, titanium dioxide, silver, and gold nanoparticles on the activity of microbial communities intended in wastewater treatment. J Hazard Mater 199-200:64-72. doi:10.1016/j.jhazmat.2011.10.057

Ge M, Guo C, Zhu X, Ma L, Han Z, Hu W, Wang Y (2009) Photocatalytic degradation of methyl orange using $\mathrm{ZnO} / \mathrm{TiO}_{2}$ composites. Front Environ Sci Eng China 3:271-280

Gou L, Murphy CJ (2003) Solution-phase synthesis of $\mathrm{Cu}_{2} \mathrm{O}$ nanocubes. Nano Lett 3:231-234

Grčić I, Li Puma G (2013) Photocatalytic degradation of water contaminants in multiple photoreactors and evaluation of reaction kinetic constants independent of photon absorption, irradiance, reactor geometry, and hydrodynamics. Environ Sci Technol 47:13702-13711

Gupta K et al (2011) Ceria associated manganese oxide nanoparticles: synthesis, characterization and arsenic (V) sorption behavior. Chem Eng J 172:219-229

Habibi MH, Sheibani R (2010) Preparation and characterization of nanocomposite $\mathrm{ZnO}-\mathrm{Ag}$ thin film containing nano-sized $\mathrm{Ag}$ particles: influence of preheating, annealing temperature and silver content on characteristics. J Sol-Gel Sci Technol 54:195-202

He S, Guo Z, Zhang Y, Zhang S, Wang J, Gu N (2007) Biosynthesis of gold nanoparticles using the bacteria Rhodopseudomonas capsulata. Mater Lett 61:3984-3987. doi:10.1016/j.matlet.2007. 01.018

Heidenreich S, Büttner H, Ebert F (2003) Aerosole und ihre technische Bedeutung. Chem Ing Tech 75:1787-1809. doi:10. 1002/cite.200306141

Hirakawa T, Kamat PV (2005) Charge separation and catalytic activity of $\mathrm{Ag} @ \mathrm{TiO}_{2}$ core-shell composite clusters under UVirradiation. J Am Chem Soc 127:3928-3934

Hossaini H, Moussavi G, Farrokhi M (2014) The investigation of the LED-activated FeFNS- $\mathrm{TiO}_{2}$ nanocatalyst for photocatalytic degradation and mineralization of organophosphate pesticides in water. Water Res 59:130-144. doi:10.1016/j.watres.2014.04. 009

Janaki V, Vijayaraghavan K, Oh B-T, Lee K-J, Muthuchelian K, Ramasamy AK, Kamala-Kannan S (2012) Starch/polyaniline nanocomposite for enhanced removal of reactive dyes from synthetic effluent. Carbohydr Polym 90:1437-1444. doi:10. 1016/j.carbpol.2012.07.012

Jia T, Wang W, Long F, Fu Z, Wang H, Zhang Q (2009) Synthesis, characterization, and photocatalytic activity of $\mathrm{Zn}$-doped $\mathrm{SnO}_{2}$ hierarchical architectures assembled by nanocones. J Phys Chem C 113:9071-9077 
Jonidi-Jafari A, Shirzad-Siboni M, Yang J-K, Naimi-Joubani M, Farrokhi M (2015) Photocatalytic degradation of diazinon with illuminated $\mathrm{ZnO}-\mathrm{TiO}_{2}$ composite. J Taiwan Inst Chem Eng 50:100-107. doi:10.1016/j.jtice.2014.12.020

Kalishwaralal K, Deepak V, Ram Kumar Pandian S, Kottaisamy M, BarathManiKanth S, Kartikeyan B, Gurunathan S (2010) Biosynthesis of silver and gold nanoparticles using Brevibacterium casei. Colloids Surf B 77:257-262. doi:10.1016/j. colsurfb.2010.02.007

Khadivi Derakhshan F, Dehnad A, Salouti M (2012) Extracellular biosynthesis of gold nanoparticles by metal resistance bacteria: streptomyces griseus. Synth React Inorg Met Org Nano Met Chem 42:868-871

Kim YK, Park H (2011) Light-harvesting multi-walled carbon nanotubes and $\mathrm{CdS}$ hybrids: application to photocatalytic hydrogen production from water. Energy Environ Sci 4:685-694

Kim K-S, Demberelnyamba D, Lee H (2004) Size-selective synthesis of gold and platinum nanoparticles using novel thiol-functionalized ionic liquids. Langmuir 20:556-560

Kong P, Pfender E (1997) Plasma processes. In: Weimer A (ed) Carbide, nitride and boride materials synthesis and processing. Springer, Netherlands, pp 359-387. doi:10.1007/978-94-0090071-4_14

Kumar RV, Diamant Y, Gedanken A (2000) Sonochemical synthesis and characterization of nanometer-size transition metal oxides from metal acetates. Chem Mater 12:2301-2305

Kun R, Mogyorósi K, Dékány I (2006) Synthesis and structural and photocatalytic properties of $\mathrm{TiO}_{2} /$ montmorillonite nanocomposites. Appl Clay Sci 32:99-110

Kwon S, Fan M, Cooper AT, Yang H (2008) Photocatalytic applications of micro- and nano- $\mathrm{TiO}_{2}$ in environmental engineering. Crit Rev Environ Sci Technol 38:197-226. doi:10.1080/ 10643380701628933

Lakshmi GC, Ananda S, Somashekar R, Ranganathaiah C (2012) Synthesis of $\mathrm{ZnO} / \mathrm{MgO}$ nanocomposites by electrochemical method for photocatalytic degradation kinetics of eosin yellow dye. Int J Nano Sci Nanotechnol 3:47-63

Landfester K (2001) The generation of nanoparticles in miniemulsions. Adv Mater 13:765-768. doi:10.1002/15214095(200105)13:10<765:AID-ADMA765>3.0.CO;2-F

Lemyre J-L, Ritcey AM (2005) Synthesis of lanthanide fluoride nanoparticles of varying shape and size. Chem Mater 17:3040-3043

Li $\mathrm{H}$ et al (2007) Mesoporous titania spheres with tunable chamber structure and enhanced photocatalytic activity. J Am Chem Soc 129:8406-8407

Li H, Wang G, Zhang F, Cai Y, Wang Y, Djerdj I (2012a) Surfactantassisted synthesis of $\mathrm{CeO}_{2}$ nanoparticles and their application in wastewater treatment RSC. Advances 2:12413-12423

Li J, Wang T, Du X (2012b) Preparation of visible light-driven $\mathrm{SnS}_{2} /$ $\mathrm{TiO}_{2}$ nanocomposite photocatalyst for the reduction of aqueous Cr(VI). Sep Purif Technol 101:11-17. doi:10.1016/j.seppur. 2012.09.014

Li Y, Zhou X, Chen W, Li L, Zen M, Qin S, Sun S (2012c) Photodecolorization of rhodamine $\mathrm{B}$ on tungsten-doped $\mathrm{TiO}_{2} /$ activated carbon under visible-light irradiation. J Hazard Mater 227:25-33

Li W, Song G, Xie F, Chen M, Zhao Y (2013) Preparation of spherical $\mathrm{ZnO} / \mathrm{ZnS}$ core/shell particles and the photocatalytic activity for methyl orange. Mater Lett 96:221-223. doi:10.1016/ j.matlet.2013.01.077

Li D, Zheng H, Wang Q, Wang X, Jiang W, Zhang Z, Yang Y (2014) A novel double-cylindrical-shell photoreactor immobilized with monolayer $\mathrm{TiO}_{2}$-coated silica gel beads for photocatalytic degradation of rhodamine B and methyl orange in aqueous solution. Sep Purif Technol 123:130-138

Lin $\mathrm{Y}$ et al (2012) Ternary Graphene- $\mathrm{TiO}_{2}-\mathrm{Fe}_{3} \mathrm{O}_{4}$ nanocomposite as a recollectable photocatalyst with enhanced durability. Eur $\mathrm{J}$ Inorg Chem 2012:4439-4444

Liu X, Pan L, Lv T, Zhu G, Lu T, Sun Z, Sun C (2011) Microwaveassisted synthesis of $\mathrm{TiO}_{2}$-reduced graphene oxide composites for the photocatalytic reduction of $\mathrm{Cr}(\mathrm{vi}) \mathrm{RSC}$. Advances $1: 1245-1249$

Liz-Marzán L, Kamat P (2003) Nanoscale materials. In: Liz-Marzán L, Kamat P (eds) Nanoscale materials. Springer, US, pp 1-3. doi:10.1007/0-306-48108-1_1

Lui G, Liao J-Y, Duan A, Zhang Z, Fowler M, Yu A (2013) Graphene-wrapped hierarchical $\mathrm{TiO}_{2}$ nanoflower composites with enhanced photocatalytic performance. J Mater Chem A 1:12255-12262

Ma W, Ma R, Liang J, Wang C, Liu X, Zhou K, Sasaki T (2014) Layered zinc hydroxide nanocones: synthesis, facile morphological and structural modification, and properties. Nanoscale 6:13870-13875

Majedi FS et al (2012) Microfluidic synthesis of chitosan-based nanoparticles for fuel cell applications. Chem Commun 48:7744-7746

Martínez C, Canle LM, Fernández MI, Santaballa JA, Faria J (2011) Aqueous degradation of diclofenac by heterogeneous photocatalysis using nanostructured materials. Appl Catal B 107:110-118. doi:10.1016/j.apcatb.2011.07.003

Mekasuwandumrong $\mathrm{O}$, Pawinrat $\mathrm{P}$, Praserthdam $\mathrm{P}$, Panpranot J (2010) Effects of synthesis conditions and annealing posttreatment on the photocatalytic activities of $\mathrm{ZnO}$ nanoparticles in the degradation of methylene blue dye. Chem Eng J 164:77-84. doi:10.1016/j.cej.2010.08.027

Mondal K, Sharma A (2014) Photocatalytic oxidation of pollutant dyes in wastewater by $\mathrm{TiO}_{2}$ and $\mathrm{ZnO}$ nano-materials- a minireview. Nanosci Technol Mank 36-72

Naimi-Joubani M, Shirzad-Siboni M, Yang J-K, Gholami M, Farzadkia M (2015) Photocatalytic reduction of hexavalent chromium with illuminated $\mathrm{ZnO} / \mathrm{TiO}_{2}$ composite. J Ind Eng Chem 22:317-323. doi:10.1016/j.jiec.2014.07.025

Ng SH, Wang J, Wexler D, Konstantinov K, Guo ZP, Liu HK (2006) Highly reversible lithium storage in spheroidal carbon-coated silicon nanocomposites as anodes for lithium-ion batteries. Angew Chem Int Ed 45:6896-6899

Ong WL, Natarajan S, Kloostra B, Ho GW (2013) Metal nanoparticle-loaded hierarchically assembled $\mathrm{ZnO}$ nanoflakes for enhanced photocatalytic performance. Nanoscale 5:5568-5575

Otari SV, Patil RM, Nadaf NH, Ghosh SJ, Pawar SH (2012) Green biosynthesis of silver nanoparticles from an actinobacteria rhodococcus sp. Mater Lett 72:92-94. doi:10.1016/j.matlet.2011.12.109

Pant HR, Park CH, Pant B, Tijing LD, Kim HY, Kim CS (2012) Synthesis, characterization, and photocatalytic properties of $\mathrm{ZnO}$ nano-flower containing $\mathrm{TiO}_{2}$ NPs. Ceram Int 38:2943-2950. doi:10.1016/j.ceramint.2011.11.071

Pant B, Pant HR, Barakat NA, Park M, Jeon K, Choi Y, Kim H-Y (2013) Carbon nanofibers decorated with binary semiconductor $\left(\mathrm{TiO}_{2} / \mathrm{ZnO}\right)$ nanocomposites for the effective removal of organic pollutants and the enhancement of antibacterial activities. Ceram Int 39:7029-7035

Park BK, Jeong S, Kim D, Moon J, Lim S, Kim JS (2007) Synthesis and size control of monodisperse copper nanoparticles by polyol method. J Colloid Interface Sci 311:417-424. doi:10.1016/j.jcis. 2007.03.039

Phanikrishna Sharma MV, Sadanandam G, Ratnamala A, Durga Kumari V, Subrahmanyam M (2009) An efficient and novel porous nanosilica supported $\mathrm{TiO}_{2}$ photocatalyst for pesticide 
degradation using solar light. J Hazard Mater 171:626-633. doi:10.1016/j.jhazmat.2009.06.040

Phanikrishna Sharma MV, Durga Kumari V, Subrahmanyam M (2010) $\mathrm{TiO}_{2}$ supported over porous silica photocatalysts for pesticide degradation using solar light: part 2. Silica prepared using acrylic acid emulsion. J Hazard Mater 175:1101-1105. doi:10.1016/j.jhazmat.2009.10.056

Qin F et al (2014) Size-tunable fabrication of multifunctional $\mathrm{Bi}_{2} \mathrm{O}_{3}$ porous nanospheres for photocatalysis, bacteria inactivation and template-synthesis. Nanoscale 6:5402-5409

Sangari M, Umadevi M, Mayandi J, Anitha K, Pinheiro JP (2015) Photocatalytic and antimicrobial activities of fluorine doped $\mathrm{TiO}_{2}$-carbon nano cones and disc composites. Mater Sci Semicond Process 31:543-550

Sathish Kumar PS, Sivakumar R, Anandan S, Madhavan J, Maruthamuthu P, Ashokkumar M (2008) Photocatalytic degradation of Acid Red 88 using $\mathrm{Au}-\mathrm{TiO}_{2}$ nanoparticles in aqueous solutions. Water Res 42:4878-4884. doi:10.1016/j.watres.2008. 09.027

Shaligram NS, Bule M, Bhambure R, Singhal RS, Singh SK, Szakacs G, Pandey A (2009) Biosynthesis of silver nanoparticles using aqueous extract from the compactin producing fungal strain. Process Biochem 44:939-943. doi:10.1016/j.procbio.2009.04. 009

Shankar MV, Anandan S, Venkatachalam N, Arabindoo B, Murugesan V (2004) Novel thin-film reactor for photocatalytic degradation of pesticides in an aqueous solution. $\mathrm{J}$ Chem Technol Biotechnol 79:1279-1285

Shen YF, Tang J, Nie ZH, Wang YD, Ren Y, Zuo L (2009) Preparation and application of magnetic $\mathrm{Fe}_{3} \mathrm{O}_{4}$ nanoparticles for wastewater purification. Sep Purif Technol 68:312-319. doi:10. 1016/j.seppur.2009.05.020

Sher Shah MSA, Park AR, Zhang K, Park JH, Yoo PJ (2012) Green synthesis of biphasic $\mathrm{TiO}_{2}$-reduced graphene oxide nanocomposites with highly enhanced photocatalytic activity. ACS Appl Mater Interfaces 4:3893-3901

Shirzad Siboni M, Samadi M-T, Yang J-K, Lee S-M (2012) Photocatalytic removal of $\mathrm{Cr}(\mathrm{VI})$ and $\mathrm{Ni}(\mathrm{II})$ by $\mathrm{UV} / \mathrm{TiO}_{2}$ : kinetic study. Desalination Water Treat 40:77-83

Singh V, Pandey S, Singh SK, Sanghi R (2009) Removal of cadmium from aqueous solutions by adsorption using poly(acrylamide) modified guar gum-silica nanocomposites. Sep Purif Technol 67:251-261. doi:10.1016/j.seppur.2009.02.023

Soltani N et al (2012) Visible light-induced degradation of methylene blue in the presence of photocatalytic $\mathrm{ZnS}$ and $\mathrm{CdS}$ nanoparticles. Int J Mol Sci 13:12242-12258

Song Y, Hormes J, Kumar CS (2008) Microfluid Synth Nanomater Small 4:698-711

Sun Z, Chen Y, Ke Q, Yang Y, Yuan J (2002) Photocatalytic degradation of a cationic azo dye by $\mathrm{TiO}_{2}$ /bentonite nanocomposite. J Photochem Photobiol, A 149:169-174. doi:10.1016/ S1010-6030(01)00649-9

Sun Q, Li H, Zheng S, Sun Z (2014) Characterizations of nano$\mathrm{TiO}_{2} /$ diatomite composites and their photocatalytic reduction of aqueous Cr(VI). Appl Surf Sci 311:369-376. doi:10.1016/j. apsusc.2014.05.070

Tajizadegan H, Jafari M, Rashidzadeh M, Saffar-Teluri A (2013) A high activity adsorbent of $\mathrm{ZnO}-\mathrm{Al}_{2} \mathrm{O}_{3}$ nanocomposite particles: synthesis, characterization and dye removal efficiency. Appl Surf Sci 276:317-322. doi:10.1016/j.apsusc.2013.03.089

Tang Y et al (2012) Hierarchical $\mathrm{TiO}_{2}$ nanoflakes and nanoparticles hybrid structure for improved photocatalytic activity. J Phys Chem C 116:2772-2780

Tavakoli A, Sohrabi M, Kargari A (2007) A review of methods for synthesis of nanostructured metals with emphasis on iron compounds. Chem Pap 61:151-170. doi:10.2478/s11696-0070014-7

Terada Y, Suzuki Y, Tohno S (2012) Synthesis and characterization of $\mathrm{TiO}_{2}$ powders by electrospray pyrolysis method. Mater Res Bull 47:889-895. doi:10.1016/j.materresbull.2011.11.032

Voigt A, Sundmacher K (2007) Herstellung maßgeschneiderter Nanopartikel durch Fällung in Mikroemulsionen. Chem Ing Tech 79:229-232. doi:10.1002/cite.200600135

Wang C-C, Lee C-K, Lyu M-D, Juang L-C (2008a) Photocatalytic degradation of C.I. basic violet 10 using $\mathrm{TiO}_{2}$ catalysts supported by $Y$ zeolite: an investigation of the effects of operational parameters. Dyes Pigm 76:817-824. doi:10.1016/j.dyepig.2007.02.004

Wang Y, Li X, Wang N, Quan X, Chen Y (2008b) Controllable synthesis of $\mathrm{ZnO}$ nanoflowers and their morphology-dependent photocatalytic activities. Sep Purif Technol 62:727-732

Wang Y, Shi R, Lin J, Zhu Y (2011) Enhancement of photocurrent and photocatalytic activity of $\mathrm{ZnO}$ hybridized with graphite-like C3N4. Energy Environ Sci 4:2922-2929. doi:10.1039/ C0EE00825G

Wang X, Shi F, Huang W, Fan C (2012) Synthesis of high quality $\mathrm{TiO}_{2}$ membranes on alumina supports and their photocatalytic activity. Thin Solid Films 520:2488-2492

Wang RX, Zhu Q, Wang WS, Fan CM, Xu AW (2015) $\mathrm{BaTiO}_{3}$ graphene nanocomposites: synthesis and visible light photocatalytic activity. New J Chem 39(6):4407-4413

Woan K, Pyrgiotakis G, Sigmund W (2009) Photocatalytic carbonnanotube- $\mathrm{TiO}_{2}$ composites. Adv Mater 21:2233-2239

Xia Y, Li F, Jiang Y, Xia M, Xue B, Li Y (2014) Interface actions between $\mathrm{TiO}_{2}$ and porous diatomite on the structure and photocatalytic activity of $\mathrm{TiO}_{2}$-diatomite. Appl Surf Sci 303:290-296. doi:10.1016/j.apsusc.2014.02.169

Xiaodan Y, Qingyin W, Shicheng J, Yihang G (2006) Nanoscale ZnS/ $\mathrm{TiO}_{2}$ composites: preparation, characterization, and visible-light photocatalytic activity. Mater Charact 57:333-341. doi:10.1016/ j.matchar.2006.02.011

Xu Y, Jia J, Zhong D, Wang Y (2009) Degradation of dye wastewater in a thin-film photoelectrocatalytic (PEC) reactor with slantplaced $\mathrm{TiO}_{2} / \mathrm{Ti}$ anode. Chem Eng J 150:302-307

Xu Y, Zhong D, Jia J, Li K, Li J, Quan X (2013) Dual slant-placed electrodes thin-film photocatalytic reactor: enhanced dye degradation efficiency by self-generated electric field. Chem Eng J 225:138-143

Xue X, Zang W, Deng P, Wang Q, Xing L, Zhang Y, Wang ZL (2015) Piezo-potential enhanced photocatalytic degradation of organic dye using $\mathrm{ZnO}$ nanowires. Nano Energy 13:414-422. doi:10.1016/j.nanoen.2015.02.029

Yang J, Lee S, Farrokhi M, Giahi O, Shirzad Siboni M (2012) Photocatalytic removal of $\mathrm{Cr}(\mathrm{VI})$ with illuminated $\mathrm{TiO}_{2}$. Desalination Water Treat 46:375-380

Yuan J, Choo ESG, Tang X, Sheng Y, Ding J, Xue J (2010) Synthesis of $\mathrm{ZnO}-\mathrm{Pt}$ nanoflowers and their photocatalytic applications. Nanotechnology 21:185606

Zhang D, Zeng F (2010) Synthesis of an Ag-ZnO nanocomposite catalyst for visible light-assisted degradation of a textile dye in aqueous solution. Res Chem Intermed 36:1055-1063

Zhang Y, Crittenden JC, Hand DW, Perram DL (1994) Fixed-bed photocatalysts for solar decontamination of water. Environ Sci Technol 28:435-442

Zhang M, Sheng G, Fu J, An T, Wang X, Hu X (2005) Novel preparation of nanosized $\mathrm{ZnO}-\mathrm{SnO}_{2}$ with high photocatalytic activity by homogeneous co-precipitation method. Mater Lett 59:3641-3644

Zhang YC, Du ZN, Li SY, Zhang M (2010) Novel synthesis and high visible light photocatalytic activity of $\mathrm{SnS}_{2}$ nanoflakes from $\mathrm{SnCl} 22 \mathrm{H}_{2} \mathrm{O}$ and S powders. Appl Catal B 95:153-159 
Zhang YC, Li J, Zhang M, Dionysiou DD (2011) Size-tunable hydrothermal synthesis of $\mathrm{SnS}_{2}$ nanocrystals with high performance in visible light-driven photocatalytic reduction of aqueous Cr(VI). Environ Sci Technol 45:9324-9331

Zhang J, Zhu Z, Tang Y, Feng X (2013) Graphene encapsulated hollow $\mathrm{TiO}_{2}$ nanospheres: efficient synthesis and enhanced photocatalytic activity. J Mater Chem A 1:3752-3756
Zhu J-J, Wang H, Xu S, Chen H-Y (2002) Sonochemical method for the preparation of monodisperse spherical and rectangular lead selenide nanoparticles. Langmuir 18:3306-3310 